\title{
Orta Gelir Tuzağı Bağlamında İhracatta Ürün Çeşitliliği ile Ekonomik Büyüme Arasındaki İlişkinin İncelenmesi ${ }^{1}$
}

\author{
Müge MANGA \\ Erzincan Binali Yıldırım Üniversitesi, İktisadi ve İdari Bilimler Fakültesi, İktisat Bölümü \\ mangamuge@gmail.com,ORCID:0000-0003-2675-2182
}

\begin{abstract}
$\ddot{\mathbf{O} z}$
Orta gelir tuzağı (OGT), ülkelerin belirli bir zaman diliminde aynı gelir grubunda kalıp uluslararası rekabet düzeyini yitirmiş olması şeklinde ifade edilen bir kavramdır. Kanchoochat ve Intarakumnerd (2014) çalışmasında, OGT'den çıkış amacıyla ifade edilen önemli stratejilerden biri, ülkelerin ihracat kompozisyonlarında çeşitliliğe yönelmeleri gerektiği şeklindedir. İhracat kompozisyonun çeşitlendirilmesinin, OGT'e girme riskine etkisinin test edilmesi amaciyla mevcut çalışmada, 1995-2017 dönemi için Robertson ve Ye (2013)'nin OGT önerisine göre seçilmiş ülkeler, orta gelir tuzağında olan (OGT) ve orta gelir tuzağından kaçan ülkeler (KOGT) olmak üzere ikiye ayrılmaktadır. Yapılan analizde, ihracat kompozisyonunun çeşitliliğini gösteren Herfindahl-Hirschman Endeksi ile ekonomik büyüme arasındaki ilişki panel veri analiz yöntemleri ile test edilmektedir. Elde edilen sonuçlar, orta gelir tuzağında olan ülkelerin ekonomik büyümelerinin ihracatta sağlanacak ürün çeşitliliğinden pozitif, orta gelir tuzağından kaçan ülkelerin ise negatif şekilde etkilendiği yönündedir. Yapılan analizin bulguları, orta gelirli ülkelerin ihracatta ürün çeşitliliğine, orta gelir tuzağından kaçan ülkelerin ise ihracatta uzmanlaşmaya yönelmeleri gerektiğini göstermektedir.
\end{abstract}

Anahtar Kelimeler: İhracat Çeşitliliği, Orta Gelir Tuzağı, Orta Gelir Tuzağındaki Ülkeler, Orta Gelir Tuzağından Kaçan Ülkeler

Jel Sinıflandırması: F14, F40, C23

An Investigation of the Relationship between Export Product Diversification and Economic Growth in the context of Middle Income Trap ${ }^{2}$

\begin{abstract}
The concept of middle income trap (OGT) is the situation in which countries have remained in the same income group for a long time and have lost international competitiveness. Kanchoochat and Intarakumnerd (2014) indicate that countries should move towards diversity in their export composition to escape from the OGT. In the study, following Robertson and Ye (2013)'s work, selected countries for the period 1995-2017 are divided into two groups: countries in the OGT and countries which escaped from the OGT (KOGT). In the analysis, the relationship between Herfindahl-Hirschman Index and economic growth examined employing panel data analysis. The results show that while the economies of countries with OGT are affected by the export diversity positively, the countries escaped from OGT (KOGT) are negatively. The findings show that middle income countries should focus on product diversification in exports and countries that escaped from middle income countries should focus on export specialization.
\end{abstract}

Keywords: Export diversificiation, Middle Income Trap, Middle Income Trap Countries, NonMiddle Income Trap Countries

Jel Classification Codes: F14, F40, C23

\footnotetext{
${ }^{1} \mathrm{Bu}$ çalışma, Çukurova Üniversitesi, "Ekonomik Büyüme, Sanayileşme Ve Orta Gelir Tuzağı İlişkisi: İnovasyon Temelli Çıkış Stratejileri Üzerine Ampirik Analizler" adlı doktora tezinden türetilmiștir.

${ }^{2}$ Extended abstract is presented at the end of the article.
}

Geliş Tarihi (Received): 16.11.2018 - Kabul Tarihi (Accepted): 11.04.2019

\section{Atıfta bulunmak için/Cite this paper:}

Manga, M. (2019). Orta Gelir Tuzağı Bağlamında İhracatta Ürün Çeşitliliği ile Ekonomik Büÿ̈me Arasındaki İlişkinin İncelenmesi. Çankırı Karatekin Üniversitesi İ̉BF Dergisi. 9 (1), 145 168. 


\section{Giriș}

Ülkelerin tarihsel süreçte yaşadığı ekonomik çöküşlerini konu alan Pritchett (2000), Reddy ve Miniou (2006), Rodrik (1999); Ros (2005) ve Hausmann, vd. (2008) gibi çalışmalarından farklı olarak orta gelir tuzağı kavramı, ilk kez Dünya Bankası için Gill ve Kharas tarafından hazırlanan "An East Asian RenaissanceIdeas For Economic Growth (Doğu Asya Rönesans1- Ekonomik Gelişme İçin Fikirler) " adlı raporda dile getirilmiştir. Bu raporda, 19. YY sonrasında ciddi bir büyüme ve entegrasyon sürecine giren, orta gelir seviyesine yükselen ancak sonraki dönemlerde uluslararası rekabet düzeylerine ayak uyduramayı orta gelir düzeyinde sıkışan ülkelerden orta gelir tuzağına düşen ülke olarak bahsedilerek bu ülkeler çeşitli önerilerde bulunulmaktadır (Gill ve Kharas, 2007, s. 1-18).

Orta gelir tuzağının teorik altyapısı birçok çalışmadan oluşmaktadır. Genel olarak, orta gelir tuzağı kavramını açıklayan iki temel yaklaşım söz konusu olduğu söylenilebilir. Bunlar, orta gelir tuzağı kavramını arz yönüyle inceleyen Kharas ve Kohli (2011) yaklaşımı ve Lin (2012) tarafından ortaya atılan yaklaşımlardır. Kharas ve Kohli (2011) yaklaşımında, ülkelerin esas aldığı kalkınma stratejisinin, düşük gelirden orta gelirli ülke statüsüne geçerken değişmesi gerektiği ifade edilirken, CAF-Karşılaştırmalı Üstünlük Takip Yaklaşımı ve CAD-Karşılaştırmalı Üstünlük Karşıtı Yaklaşımı (Comparative Advantage Following) olarak ikiye ayrılan Lin (2012) yaklaşımına göre ise herhangi bir strateji değişikliğine gerek duyulmamaktadır (Islam, 2013, s. 1-6). Genel olarak bu çerçevede yapılan çalışmalara ve ülkelerin orta gelir tuzağına düşmesinde baz alınan eşik değerlerine Tablo 1'de yer verilmektedir.

Ayrıca orta gelir tuzağının teorik çerçevesinin oluşmasını sağlayan Maltusyen Tuzak, Lewis'in Dual (ikili) Yapı Modeli ve Solow'un büyüme teorisi gibi “düşük düzey denge tuzağı modelleri”nin yanısıra (Ay, vd. 2016, s. 282-283) orta gelir tuzağına ekonomik gelişme evresi, gelir eşitsizliği ve politik ekonomi bakımından ele alan, Ohno (2009), Aoiki (2011), Tho (2013), Dewitte (2014), Agenor vd. (2012) ve Egawa (2013), . Islam (2015), Hartwell (2013), Doner ve Schneider (2016), Foxley ve Sossdoff (2011) ve Luiz (2016) gibi çalışmalarda bahsedebilmek mümkündür. 


\section{Tablo 1:Orta Gelir Tuzağı Üzerine Yapılan Yaklaşımların Özeti}

\begin{tabular}{|c|c|c|}
\hline Yazarlar & Tanım & Orta Gelir Eşik Aralı̆̆ \\
\hline \multirow{5}{*}{$\begin{array}{l}\text { Eichengreen } v d . \\
\quad(2011)\end{array}$} & Büyüme yavaşlaması kriterleri & \multirow{5}{*}{$\begin{array}{l}>10,000 \$(2005 \text { y1lı } \\
\text { sabit fiyatlarına göre })\end{array}$} \\
\hline & $g_{t, t-n} \geq 0.035, g_{t, t+n}-g_{t, t-n} \geq 0.02, y_{t} \geq$ & \\
\hline & 10.000 & \\
\hline & Büyüme yavaşlaması (KBGSYH) 15,000- & \\
\hline & $16,000 \$$ oluşur. & \\
\hline \multirow{5}{*}{$\begin{array}{l}\text { Eichengreen vd. } \\
\text { (2013) }\end{array}$} & Büyüme yavaşlaması & \multirow{5}{*}{$\begin{array}{l}>10,000 \$(2005 \text { yilı } \\
\text { sabit fiyatlarına göre })\end{array}$} \\
\hline & $g_{t, t-n} \geq 0.035, g_{t, t+n}-g_{t, t-n} \geq 0.02, y_{t} \geq$ & \\
\hline & 10.000 & \\
\hline & Büyüme yavaşlaması (KBGSYH) 10,000- & \\
\hline & $11,000 \$$ ile $15,000-16,000 \$$ arasında oluşur. & \\
\hline \multirow[t]{2}{*}{ Felipe vd. (2012) } & $\begin{array}{l}\text { Düşük orta gelir tuzağı için, }>28 \text { yıl düşük } \\
\text { orta gelir grubunda kalması gerekir. Düşük } \\
\text { orta gelir tuzağına düşmemek için yıllık } \\
\text { ortalama } \% 4,7 \text { oranında büyümesi gereklidir. }\end{array}$ & \multirow[t]{2}{*}{$\begin{array}{l}\text { 2,000 \$- } 11,750 \$ \\
\text { (SAGP göre } 1990 \text { sabit } \\
\text { fiyatlar1) }\end{array}$} \\
\hline & $\begin{array}{l}\text { Yüksek orta gelir tuză̆ı için, > } 14 \text { yıl yüksek } \\
\text { orta gelir grubunda kalması gerekir. Yüksek } \\
\text { orta gelir tuzağına düşmemek için yıllık } \\
\text { ortalama \%3.5 büyümesi gereklidir. }\end{array}$ & \\
\hline \multirow[t]{2}{*}{ Aiyar vd. (2013) } & $\begin{array}{l}\text { Büyüme yavaşlaması } t \text { dönemdeki } \text { res }_{t}^{i} \\
\text { değerinin } t-1 \text { ve } t+1 \text { dönemine göre daha }\end{array}$ & \\
\hline & küçük olması & $\begin{array}{c}\text { (2005 sabit fiyatlarına } \\
\text { göre) }\end{array}$ \\
\hline \multirow[t]{2}{*}{ Woo vd. (2012) } & $\% 55>$ CUI $>\% 20$ ve & \multirow{2}{*}{$\begin{array}{c}\% 55>\text { CUI }>\% 20(1990 \\
\text { fiyatlariyla Geary- } \\
\text { Khamis \$) }\end{array}$} \\
\hline & $>50$ y1l & \\
\hline \multirow[t]{2}{*}{$\begin{array}{c}\text { Robertson ve Ye } \\
\text { (2013) }\end{array}$} & $\begin{array}{c}\text { i ülkesinin t dönemdeki kişi başına gelir } \\
\text { serisinin farkı referans alınan ülkenin t } \\
\text { dönemdeki kişi başına gelir serisinin farkı } \\
\text { arasındaki eşitliğin }\end{array}$ & \multirow[t]{2}{*}{$\begin{array}{c}\% 8-\% 36(2005 \text { yılı } \\
\text { sabit fiyatlarına göre })\end{array}$} \\
\hline & $x_{i, t} \equiv y_{i, t}-y_{r, t}$ olmas1 durumunda & \\
\hline Bulman vd. (2014) & $\begin{array}{l}\text { >49 yıl boyunca ABD kişi başına gelir } \\
\text { düzeyinin } \% 10-\% 50 \text { arasında olması }\end{array}$ & $\begin{array}{l}\% 10-\% 50 \text { ABD - KBG } \\
\text { (2005 sabit fiyatlariyla) }\end{array}$ \\
\hline
\end{tabular}

Kaynak: Glawe ve Wagner, 2016, s. 14-18 
Gelir dağılımında, sektörel, coğrafi dağılımda adaletsizlik, kapsayıcı büyüme, çevreci büyüme ve ekonomik bağlamda çeşitli ortak sorunları olan orta gelirli ülkelerin orta gelir tuzağından çıkabilmeleri için uygulamaları gereken önemli stratejileri konu alan Kanchoochat ve Intarakumnerd (2014) çalışmasında, "İhracat Kompozisyonun Değiştirilmesi ve Çeşitlendirilmesi" gerektiği ifade edilmektedir. Bu bağlamda yapılan çalışmada, Kanchoochat ve Intarakumnerd (2014) çalışmasında vurgulanan ve orta gelir tuzağından çıkışta önemli bir çıkış stratejisi olan, ihracat ürünlerin çeşitlendirilmesinin (export diversificiation) ekonomik büyüme üzerindeki etkisinin, orta gelir tuzağında olan (OGT) ve orta gelir tuzağından kaçan (KOGT) seçilmiş ülkelerden oluşan ülke grupları üzerinde sınamasının yapılması amaçlanmaktadır.

Yapılan çalışmanın giriş bölümünde, orta gelir tuzağı ile ilgili genel bir değerlendirme yapılarak, ihracatta ürün çeşitlendirmesi ve değiştirilmesinin önemi üzerine vurgu yapılmaktadır. Çalışmanın ikinci bölümünde, ihracatta ürün çeşitliliği ve ekonomik büyüme arasındaki ilişki incelenerek, üçüncü bölümde uygulanan veri ve yöntemden bahsedilmektedir. Çalışmanın sonraki bölümlerinde ise, yapılan analiz çerçevesinde elde edilen bulgulara ve politika önerileri değinilen sonuç bölümüne yer verilmektedir.

\section{2.İhracatta Ürün Çeşitliliği ve Ekonomik Büyüme İlişkisi}

İhracatta ürün çeşitliliği genel olarak ülkenin ihracat kompozisyonu ve yapısının değişmesi olarak tanımlanmaktadır. Ali vd. (1991)'e göre ihracat çeşitliliği, ihracat ürün grubundaki veya ihracat bölgelerindeki değişimi ifade ederken, Berthelemy ve Chauvin (2000)'e göre, üretimin sektörel yaygınlaşmasını, Samen (2010)'a göre ise, ülkenin ihraç yapısının geleneksel olan ihracattan geleneksel olmayan ihraç ürünlerine doğru gelişmesini ifade etmektedir (Samen, 2010, s. 4). $\mathrm{Bu}$ süreç, mevcut ihraç mallarının değiştirilmesi veya mevcut malların yenilik ve teknolojik yapılarının genişletilmesi yoluyla sağlanabilmektedir. Dennis ve Shepherd (2007)'e göre ihracat çeşitliliği, ülkenin ihracat ürünlerindeki genişlemeyi ifade etmektedir (Dennis ve Shepherd, 2007, s. 5). Samen (2010) çalışmasında, ithal girdiden ikincil ve üçüncül sektörlere geçişi ifade eden "çapraz çeşitlenmeye" de vurgu yapılmasına rağmen, genel anlamda, ihraç çeşitliliği, yatay ve dikey olmak üzere iki farklı şekilde gerçekleştirilmektedir.

Herzer ve Nowak-Lehnmann (2006)'a göre, yatay çeşitlendirme aynı sektörde sadece birincil enerji miktarındaki artışa bağlı olan performans değişimidir. Yatay ihracat çeşitliliği ile birlikte artan ihracat sektörlerindeki mal çeşitliliği aşırı fiyat ve hacim dalgalanmalarına maruz kalmış sınırlı miktarda olan emtialara bağımlılığı azaltabilmektedir. Ayrıca ihracat çeşitlendirmesiyle ilişkili geliştirilmiş üretim teknikleri, bilgi yayılımı yoluyla diğer endüstrilere fayda sağlayarak artan uluslararası rekabetçilik, daha etkin yönetim tarzları, daha iyi organizasyon biçimleri, iş eğitimi, teknoloji gibi alanlarda bilgi dışsallığı ile 
ekonomik büyüme üzerinde pozitif yönlü bir etki sağlamaktadır (Herzer ve Nowak-Lehnmann, 2006, s. 1-2).

Dikey çeşitlendirme ise, katma değer yaratabilen bir sektörde üretim ve pazarlama süreciyle ilgili olarak mevcut emtiada kayda değer bir yenilik yaratma veya yeni bir emtianın ortaya çıkması ile ilgili bir süreçtir. Dikey çeşitlendirme, yatay çeşitlendirmede ağırlıkta olan birincil ürünlere dayalı ihracat performansından ziyade daha çok ikincil veya üçüncül sektörlere veya imalat sektörü ürünlerine doğru yapısal bir dönüşümü içerdiğinden bilgi yayılımı, uluslararası rekabet ve ekonomik istikrarın sağlanmasında daha çok etkilidir. Daha genel ifade ile dikey çeşitlendirme, yatay çeşitlendirmeye kıyasla daha gelişmiş teknoloji, sofistike ürün, politika, beceri ve başlangıç sermaye yatırımı gerektirmektedir. Ayrıca dikey çeşitlendirme yatay çeşitlendirmeden daha dinamik dişsallıklar sağlamaktadır (Pirasteh, vd. 2009,s. 108-109).

İhracatta ürün çeşitliliği ile ekonomik büyüme arasındaki ilişkiyi ele alan $\mathrm{H}$. Markowitz (1952) tarafından modern portföy seçimi teorisinden esinlenerek ortaya atılan görüşe göre, yapılan ihracat çeşitlendirmesi, bir ülkenin belirli bir ürüne olan bağımlılığını azaltmada oldukça önemlidir (Lugeiyamu, 2016, s. 5). Genel olarak portfolyo teorisi Şekil 1'deki gibi gösterilebilir.

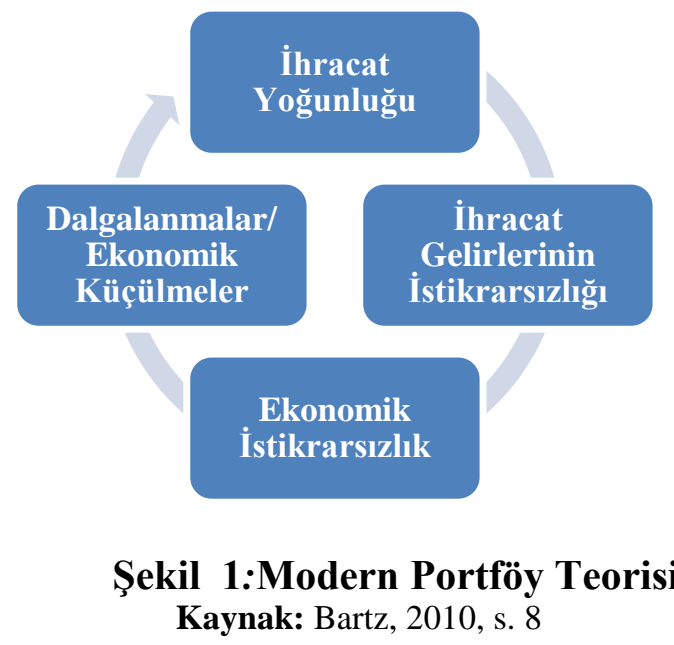

Buna göre artan ihracat yoğunluğu ekonomik istikrarsızlıklara, ekonomik dalgalanmalara ve küçülmelere yol açmaktadır. Bununla birlikte Naude ve Rassouw (2008) çalışmasına göre, ihracat çeşitliliği ile petrol, kahve ve elmas gibi çeşitli doğal kaynak türleri bakımından zengin olan ülke ekonomilerinin doğal kaynaklara aşırı bağımlı olmasından kaynaklı olarak ekonomik büyümelerinin negatif yönde etkilenmesinin (Hollanda Hastalığı (Dutch Disease)) de önüne geçilebilmektedir (Naude ve Rassouw, 2008, s. 3). 
İhracat çeşitliliği ile ekonomik büyüme arasındaki ilişkiyi ifade eden diğer bir teori ise, "Dinamik Etkiler Teorisi"dir. Şekil 2'de Dinamik Etkiler Modeline göre ihracat çeşitliliği ile ekonomik büyüme arasındaki ilişki gösterilmektedir.

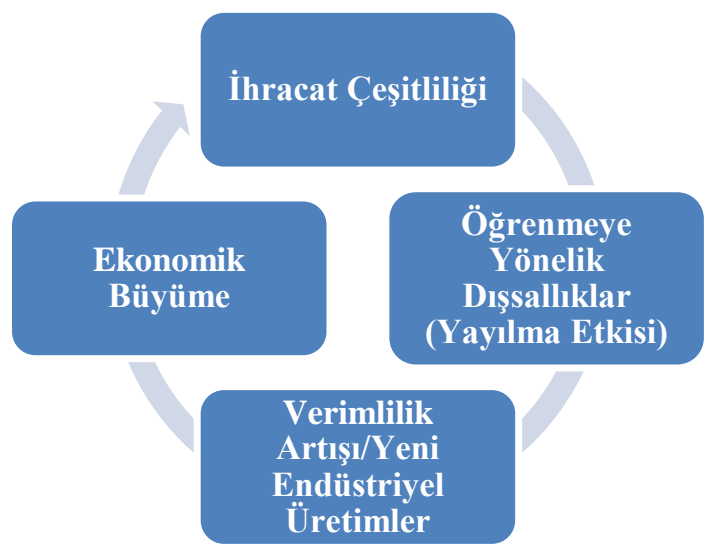

\section{Şekil 2:Dinamik Etkiler Modeli}

Kaynak: Bartz, 2010, s. 11

Dinamik Etkiler Teorisinde, Modern Portfolyo Teorisinden farklı olarak sektörel bazda oluşan ihracat çeşitliliğinin etkisinin, yayılma özelliği dolayısıyla, artan verimlilik artışı ile yeni endüstrilerin ortaya çıkabileceği, böylece, ekonomik büyümenin artacağı savunulmaktadır.

İhracatta ürün çeşitliliği ile ekonomik büyüme arasındaki ilişkiyi konu alan teorik çalışmaların yanı sıra ampirik çalışmalardan da bahsedebilmek mümkündür. Modern Portföy Teorisinin geçerliliğinin test edilmesinin amaçlandığı Hirsch ve Lev (1971) çalışmalarında, 1964-1968 yılları arasındaki Danimarka, Hollanda ve İsrail'deki 500'e yakın firma ile 1969 yılının ikinci ve üçüncü çeyreğinde yapılan görüşmelerle elde edilen veriler doğrultusunda, ihracat çeşitliliğinin ihracat gelirlerinin istikrarı için önem arz ettiğini tespit etmişlerdir. Ayrıca çalışmada, gelişmekte olan bir ülke olan İsrail'deki ihracat gelirlerinin, ihracat çeşitliliğindeki düşüklükten kaynaklı olarak Danimarka ve Hollanda'ya göre çok daha istikrarsız ve dalgalı olduğu ifade edilmiştir.

Acemoğlu ve Zilibotti (1997) çalışmalarında, bir ülkenin kalkınma aşamasında ihracat çeşitliliğinin (risk dağıtımı) önemine vurgu yapılarak, finansal kredi yapısı ile ihracat çeşitliliği arasında ilişki kurulmaktadır. Love (1986) çalışmasında, geleneksel anlamda ihracat yoğunlaşmasının, özellikle gelişmekte olan ülkelerde kısa vadeli istikrarsızlıkların ortaya çıkmasında önemli bir faktör olduğu sonucuna ulaşılmıştır. Petersson (2005)'e göre ise, Güney Afrika'daki ihracat çeşitliliği ile ekonomik büyüme arasında pozitif yönlü bir ilişki söz konusudur.

Latin Amerika üzerine yapılan Gutiérrez-de-Piñeres ve Ferrantino (2000), çalışmasında 1962-1991 yılları arasında Şili, Kolombiya, Uruguay, El Salvador, 
Paraguay, Bolivya ve Kosta Rika ülkelerinde ihracat çeşitliliği ile ekonomik büyüme arasında pozitif, ihracatta yoğunlaşma ile ekonomik büyüme arasında ise negatif yönlü ve güçlü bir ilişki olduğu sonucuna ulaşılmıştır. Matthee ve Naude (2007), 1996-2004 yılları arasında Güney Afrika'daki 354 yerleşim yeri ve 19 sektör üzerine uygulanan OLS yöntemi ile bu bölgede oluşan ihracat çeşitliliğinin ülke genelinde ekonomik büyüme artışı, yeni teknoloji ve bilgi yayılımının sağlanmasında önemli bir faktör olduğu sonucunu elde etmişlerdir. Herzer ve Nowak-Lehmann (2006), 1960-2000 yılları arasında Şili'deki ihracat çeşitliliği ile ekonomik büyüme arasındaki ilişkiyi test ettikleri çalışmalarında yapılan yatay çeşitlendirmenin yeni ürünlerin üretimi için dışsallık yarattığını ve ekonominin dinamizmini arttırdığını vurgulamışlardır. 1983-2012 yılları arasında Nijerya' daki ihracat çeşitliliği ile ekonomik büyüme arasındaki ilişkinin test edildiği Olaleye vd. (2014), çalışmasında uygulanan eşbütünleşme ve nedensellik testleri ile ihracat çeşitliliği ile ekonomik büyüme arasında güçlü bir ilişkinin olduğu sonucuna ulaşılmıştır. 1961-1988 yılları arasındaki 91 ülkedeki ihracat çeşitliliği ile ekonomik büyüme arasındaki ilişkinin üç farklı endeksten faydalanılarak test edildiği Al-Marhubi (2000)'da elde edilen sonuçlara göre ise, ilkel olmayan ihracat yapısı ve daha yüksek ihracat çeşitliliğine sahip olan gelişmiş ülkeler daha hızlı büyümektedir.

Çeviker ve Taş (2011), Türkiye'deki 1962-2008 yılları arasındaki ihracat çeşitliliği ile ekonomik büyüme arasındaki ilişkiyi analiz etmişlerdir. Yapılan çalışmada, ekonomik büyümeden ihracata, ihracattan ise ihracat çeşitlendirmesine doğru tek yönlü nedensellik ilişkisine yönelik bulgular elde edilirken, beklentilerin aksine çeşitlendirme ile ekonomik büyüme arasında herhangi bir nedensellik ilişkine ulaşılamamıştır.

Bebczuk ve Berrettoni (2006)'nin, 1962-2002 y1lları arasındaki 56 ülke üzerine yaptıkları çalışmada, toplam ihracatın, imalat sanayinin, tarımsal ve petrol ürünlerinin ihracattaki payı gibi dış ticarete dayalı değişkenler ile doğrudan yabancı yatırımlar, özel sektör kredilerinin ve sabit sermayenin GSYH'deki payı gibi makroekonomik değişkenlerden yararlanmışlardır. Elde edilen analiz sonuçlarına göre, ihracat çeşitliliğinin ülkedeki kişi başına gelir düzeyinin 11,036 \$'a yükselene kadar artış trendinin devam ettiğini, eşik değerin üzerinde oluşan gelir artışlarıyla birlikte ihracat çeşitliliğinin azalarak yoğunluğun artığı, ihracat çeşitliliği ile ekonomik büyüme arasındaki bu ilişkinin " $U$ " şeklinde olduğu ifade edilmektedir. Ayrıca yapılan analiz sonucunda, Güney Amerika ve Afrika'da ihracat yoğunluğunun diğer seçilmiş bölgelere göre çok daha yüksek olduğu sonucuna ulaşılmıştır.

Hesse (2008), 5 yıllık periyotlar halinde ayrılan 1961-2000 yılları arasındaki 99 ülke üzerine yaptığı çalışmada, GMM yönteminden faydalanılarak, beklentilere uyumlu olarak Çin, Güney Kore, Tayvan ve Tayland gibi kalkınmada başarılı olan Güney Asya ülkelerinin düşük ihracat yoğunluğuna sahip olduğu sonucuna 
ulaşılmıştır. Mudenda vd. (2014) çalışmasında, 980-2010 yılları arası için Güney Afrika ülkesindeki ihracat çeşitliliği ile ekonomik büyüme arasındaki ilişki Vektör Hata Düzeltme Modeli (VECM) yöntemiyle ele alınmış, ihracat çeşitliliği ve dışa açıklığın ekonomik büyüme ile pozitif ilişki içerisinde olduğu sonucu vurgulanmıştır. 1980-2003 yılları arasında geçiş ekonomilerinde ihracat çeşitliliği ile ekonomik büyüme arasındaki ilişkiyi test eden Agosin (2007), ihracat çeşitliliği ile ekonomik büyüme arasında anlamlı ve pozitif yönlü bir ilişki olduğu sonucuna ulaşmıştır. Ayrıca, Hausmann ve Hidalgo (2010) çalışmasında, farklı modellerden faydalanarak, ülkenin ihracat ettiği ürün sepetleri ile ürünlerin ortalama yaygınlıkları arasında ilişki olduğu ifade edilmektedir. Farklı zaman dilimleri için farklı ülkeler üzerine yapılan Fotros vd. (2013), Nicet-Chenaf ve Rougier (2008), Balaguer ve Cantavella-Jorda (2004), Bonaglia ve Fukasaku (2003), Arip, vd. (2010), Parteka ve Tamberi (2008) ve Mau (2014) çalışmalarında da benzer sonuçlar elde edilmiştir.

\section{Veri ve Yöntem}

1995-2017 dönemi için, OGT ve KOGT ülkelerindeki ihracatta ürün çeşitliliği ile ekonomik büyüme arasındaki ilişkinin analiz edilmesinin amaçlandığı bu bölümde, ülke sınıflandırılması, Robertson ve Ye (2013) çalışmasında yer alan orta gelir tuzağı önermesine göre yapılmıştır. Orta gelir tuzağı sınamasında Robertson ve Ye'nin önermesine göre daha kısıtlı sayıda ülke seçilmesinin sebebi seçilen ülkelerin, günümüzdeki gelir düzeylerini korumada istikrarlılık göstermesidir. Yapılan analizde orta gelir tuzağında yer alan ülke grubunda, Brezilya, Meksika, Malezya ve Türkiye yer alırken, orta gelir tuzağından kaçabilen ülke grubunda ise Güney Kore, Portekiz, Singapur ve Yunanistan yer almıştır. 1995-2017 yıları arasındaki ihracat çeşitliliğinin ölçümünde kullanılan Herfindahl-Hirschman Endeksi (HHI) veri seti, UNCTADSTAT veri tabanından, 2010 yılı sabit \$ fiyatlarıyla alınan kişi başına gelirdeki değişimi gösteren veri seti ise Dünya Bankası verilerinden elde edilmiştir. İhracat çeşitliği ile ekonomik büyüme arasındaki ilişkinin tespit edilmesinde ilgili çalışmalarda sıkça kullanılan HHI endeksi,

$H H I=\frac{\sqrt{\sum_{i=1}^{N}\left(\frac{x_{i}}{\sum_{i=1}^{N} x_{i}}\right)^{2}-\sqrt{\frac{1}{N}}}}{1-\sqrt{\frac{1}{N}}}$

şeklinde tahmin edilmektedir. Fonksiyonda yer alan $X_{i}$, i ürününün ihracatını, $N$ toplam ürün miktarını göstermektedir. HHI endeks değerleri $0 \leq H H I \leq 1$ arasında değerler almaktadır. İhracat sepetinde yoğunlaşma/uzmanlaşma ve çeşitliliği gösteren HHI değerinin 1'e yakın bir değer alması, yüksek bir ihracat yoğunluğunu/uzmanlaşmasını (aşırı düşük ihracat çeşitlilik) temsil ederken ve 0'a yakın değer, düşük bir ihracat yoğunluğunu/uzmanlaşmasını (yüksek ihracat çeşitliliğini) göstermektedir. Burada önemle vurgulanması gereken nokta, HHI değerinin yoğunluk ve çeşitlendirme konusunda dolaylı ve ters yönlerden 
yorumlanması gerektiğidir (Lugeiyamu, 2016, s. 12). Seçilen ülkelerin ihracat çeşitliliğini/yoğunluğunu temsil eden HHI endeksinde görülen değişimler Şekil 3 'te gösterilmektedir.
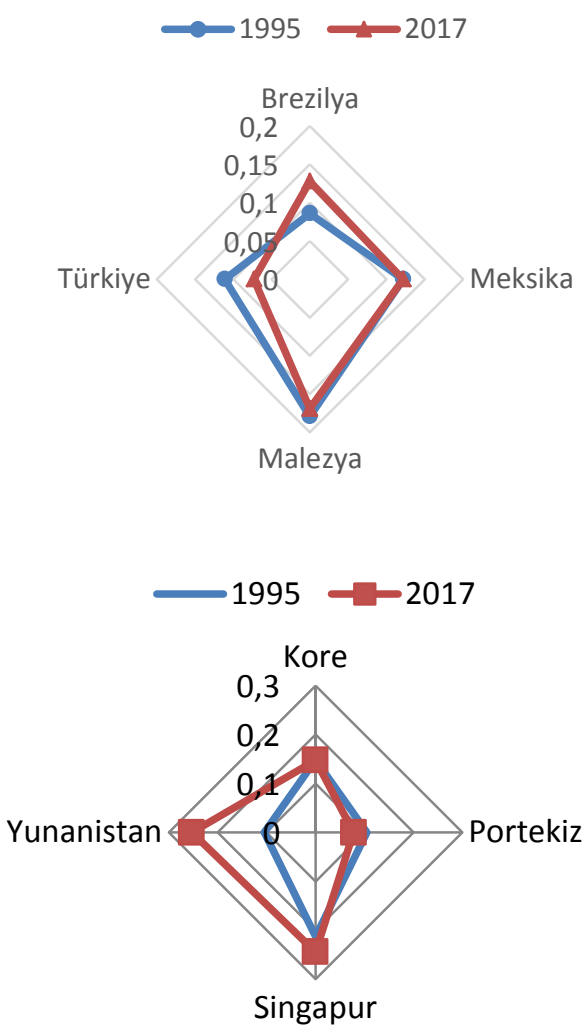

\section{Şekil 3:OGT ve KOGT Ülkelerinin HHI Değerindeki Değişimler}

Kaynak: UNCTADSTAT, 2017

Orta gelir tuzağından çıkış stratejisi olarak ifade edilen ihracatın sektörel yapısının değiştirilmesi ve çeşitlendirilmesi üzerine kullanılan ihracat çeşitliliği endeksi ile ekonomik büyüme arasındaki ilişkinin test edilmesi amacıyla Panel ARDL yönteminden faydalanılmıştır. Öncelikle, panel grubunu oluşturan kesitler arasında yatay kesit bağımlığ 1 olup olmadığı Pesaran (2004) testi ile sınanmıştır. Pesaran (2004) tarafindan türetilen ADF regresyonunun tahmininden elde edilen kalıntıların kullanıldığ birimin kendisi dışında kalan tüm birimlerle otokorelasyonu hesaplanmakta ve $\mathrm{N}$ birim boyuttaki otokorelasyon sayıs1, $\mathrm{N} * \mathrm{~N}-1$ adete kadar hesaplanmaktadır. Dengeli panel için CD testi; 


$$
C D=\sqrt{\left(\frac{2 T}{N(N-1)}\right)} \sum_{i=1}^{N-1} \sum_{j=i+1}^{N}\left(\hat{\rho}_{i j}-1\right) \square N(0,1)
$$

şeklinde hesaplanmaktadır (Tatoğlu, 2017, s. 105).

Modelde yer alan değişkenler için durağanlık testinde Panel Birim Kök testlerinden Pesaran (2007) tarafindan ortaya atılan CADF (Cross-Sectional Augmented Dickey-Fuller) testinden faydalanılmıştır. $\mathrm{T}>\mathrm{N}$ ve $\mathrm{N}>\mathrm{T}$ olması durumunda kullanılan CADF regresyonun en geneli,

$$
\Delta Y_{i t}=\alpha_{i}+\rho_{i} Y_{i, t-1}+\beta_{i} \bar{Y}_{t-1}+\sum_{j=0}^{k} \gamma_{i j} \Delta \bar{Y}_{i, t-1}+\sum_{j=0}^{k} \delta_{i j} Y_{i, t-1}+\varepsilon_{i t}
$$

şeklinde ifade edilmektedir. (3) nolu denklemde yer alan $\alpha_{i}$ deterministic trend, $\bar{Y}_{t-1}=(1 / N) \sum_{i=!}^{N} Y_{i, t-1}$ ve $t_{i}(N, T), \rho_{i}$ değeri için hesaplanan ADF istatistiğini vermektedir. CADF testinde durağanlığın sınamasında;

$H_{0}: \rho_{i}=0$ (tüm i'ler için)

$H_{1}: \beta_{i}<0 \quad\left(\mathrm{i}=1,2, \ldots . \mathrm{N}_{\mathrm{i}}\right)$ ve $\rho_{i}=0\left(\mathrm{i}=\mathrm{N}_{\mathrm{i}+1}, \mathrm{~N}_{\mathrm{i}+2} \ldots \ldots, \mathrm{N}\right)$ şeklindedir (Tatoğlu, 2017, s. 85-86).

Ayrıca Pesaran (2007) tarafindan her bir yatay kesite ait (ülkelere) birim kök test istatistiklerinin ortalaması alınarak panelin geneli için hesaplanan birim kök testlerinden Yatay kesit Genişletilmiş Im, Pesaran ve Shin (Cross-Sectionally Augmented IPS-CIPS) elde edilebilir. CADF istatistiğinin ortalaması olan CIPS;

$$
\text { CIPS }=\frac{1}{N} \sum_{i=1}^{N} t_{i}(N, T)
$$

şeklinde hesaplanabilir (Pesaran, 2007, s. 276).

$\mathrm{Bu}$ çerçevede değişkenler arasındaki uzun ve kısa dönemli ilişki Pesaran vd. (1999) tarafından geliştirilen Panel ARDL yöntemi ile analiz edilmiştir. Panel ARDL modeli grup tahmincisinin; havuzlanmış grup tahmincisi (pooled mean grup-PMG) ve grup tahmincisi (mean grup-MG) olarak çeşitli örnekleri söz 
konusudur. Yapılan çalışmada, belirlenen değişkenler arasındaki ilişki için kurulan panel ARDL denklemi;

$G S Y H_{i t}=\sum_{k=1}^{p} G S Y H_{i, t-k} \emptyset_{i k}+\sum_{k=0}^{q} H H I_{i, t-k} \partial_{i k}+\mu_{i}+\varepsilon_{i t}$

şeklinde oluşturulmaktadır.

Ayrıca, Panel ARDL yöntemi için hata düzeltme modeli;

$\Delta G S Y H_{i t}=$

$\partial_{i}\left(G S Y H_{i, t-1}-Q_{t} H H I_{i t}\right)+\sum_{k=1}^{p-1} \vartheta_{i k} \Delta G S Y H_{i, t-1}+\sum_{k=0}^{q-1} \alpha_{i k} \Delta H H I_{i, t-k}+\mu_{i}+$

$\varepsilon_{i t}$

şeklinde ifade edilebilir. Hata düzeltme modelinde yer alan $\partial_{i}$ hata düzeltme katsayısını ifade etmektedir (Öztürk ve Altınöz, 2018, s. 22).

\section{Bulgular}

Robertson ve Ye (2013) eşik değerlerine göre OGT ve KOGT iki ülke grubundaki ihracat çeşitliliği ile ekonomik büyüme arasındaki ilişkinin tespit edilmesi amaçlanmıştır. Bu çerçevede yapılan Pesaran (2004) testi sonuçları Tablo 2'de yer almaktadır.

Tablo 2: OGT ve KOGT Ülkeleri İçin Yapılan Yatay Kesit Bağımlıı̆̆ı Testi

\begin{tabular}{|l|l|l|l|}
\hline OGT & T-istatistiği & KOGT & T-istatistiği \\
\hline $\mathrm{CD}_{\mathrm{LM}}$ & $9.992 * * *$ & $\mathrm{CD}_{\mathrm{LM}}$ & $9.669 * * *$ \\
& & & \\
\hline
\end{tabular}

Not: $* * *, \% 1$ anlamlılık düzeyini göstermektedir.

Elde edilen bulgular, seçilmiş ülke gruplarını oluşturan yatay kesitler arasında ekonomik, politik vs. yönlerinden bir bağımlılı̆̆ının söz konusu olduğun göstermektedir. Yapılan analizin diğer aşamasında kurulan modeli oluşturan değişkenler için CIPS birim kök testi yapılmıştır. Yapılan birim kök testi sonuçları Tablo 3'te yer almaktadır. 
Tablo 3: Birim Kök Testi Sonuçları

\begin{tabular}{|c|c|c|}
\hline & OGT & KOGT \\
\hline LnGSYH & -1.593 & -1.165 \\
\hline$\triangle L n G S Y H$ & $-3.505 * * *$ & $-2.716 * * *$ \\
\hline LnHHI & -1.546 & -1.978 \\
\hline$\triangle L n H H I$ & $-4.253 * * *$ & $-5.041 * * *$ \\
\hline
\end{tabular}

GSYH ve HHI değişkenlerinin düzey değerinde birim köke sahip olduğu görülmektedir. $\mathrm{Bu}$ nedenle, her iki ülke grubu için yapılan fark alma işlemi sonrası tüm değişkenlerin durağan olduğu gözlemlendiğinden her iki değişkenin de I(1) olduğu söylenebilir.

Değişkenlere uygulanan birim kök testi sonrasında değiş̧kenler arasındaki uzun dönemli ilişkiyi ortaya koymak amacıyla her iki ülke grubu için uygulanan Panel ARDL testi sonuçları Tablo 4'te gösterilmektedir.

Tablo 4:Panel ARDL Testi Sonuçları

\begin{tabular}{|c|c|c|c|c|}
\hline & \multicolumn{2}{|c|}{ OGT Ülkeleri } & \multicolumn{2}{c|}{ KOGT Ülkeleri } \\
\hline Uzun Dönem & PMG & MG & PMG & MG \\
\hline InHHI & $-0.16^{* *}$ & -1.00 & $2.10^{* * *}$ & 1.23 \\
\hline ECT(-1) & $-0.35^{* * *}$ & $8.23^{* *}$ & $-0.39^{* *}$ & $8.57^{* *}$ \\
\hline Kisa Dönem & & & & \\
\hline$\Delta$ InHHI & $0.092^{* *}$ & $7.14^{* * *}$ & $-0.332^{*}$ & -4.82 \\
\hline
\end{tabular}

Not: $* * *, * *, *$ sirasıyla $\% 1, \% 5, \% 10$ düzeyindeki anlamlılığı ifade etmektedir.

Tablo 4'te yer alan sonuçlara göre, Panel ARDL/PMG ve Panel ARDL/MG tahmincisi bulguları incelendiğinde her iki ülke grubu için tahminci katsayılarını farklı olduğu görülmektedir. Panel ARDL PMG/MG tahmincilerinden hangisinin kullanılması gerektiğinin anlaşılması için Tablo 5'te bulguları yer alan Hausman testi yapılmıştır. 
Tablo 5:Hausman Testi Sonuçları

\begin{tabular}{|l|l|l|l|}
\hline & Tahminci & Chi2 & Olasılık \\
\hline OGT Ülkeleri & MG,PMG & 0.93 & 0.334 \\
\hline KOGT Ülkeleri & MG,PMG & 0.18 & 0.674 \\
\hline
\end{tabular}

Her iki ülke için uygulanan Hausman testi sonuçlarının olasılık değerlerinin \%5'ten büyük olması dolayısıyla Panel ARDL/PMG tahmincisi bulgularının kullanılması gerektiği ortaya çıkmaktadır. Panel ARDL/PMG sonuçlarına göre, OGT ülkeleri, uzun dönemde ihracat çeşitliliğini arttırmaya yönelik politikalara ihtiyaç duyarken, KOGT grubundaki ülkelerin ekonomik büyümeleri, ihracatlarını çeşitlendirmekten ziyade ihracat yoğunluğundan, belirli ürün ve ürün gruplarının ihracatında sağlanan uzmanlaşmadan pozitif yönde etkilenmektedir. Elde edilen bulgular çerçevesinde, OGT grubunun belirli bir gelir düzeyi eşiğine kadar ihracatlarında çeşitliliğe yönelmeleri gerektiği açıkça ifade edilebilir.

\section{Sonuç}

Bu çalışmada, 1995-2017 yılları arası dönem için Kanchoochat ve Intarakumnerd (2014) çalışmasında orta gelir tuzağından çıkış stratejisi olarak ifade edilen ihracatta ürün çeşittiliğinin orta gelir tuzağını gidermedeki etkisinin OGT ve KOGT ülkeleri için ayrı ayrı analiz edilerek sınanması amaçlanmıştır. Seçilen ülkelerin ayrımında Robertson ve Ye (2013) çalışmasında ifade edilen orta gelir tuzağı önermesi baz alınmıştır. İhracatta ürün çeşitliliğinin göstergesi olarak Agosin vd. (2012), Ferdous (2011) ve Fonchamnyo ve Akame (2017) gibi çalışmalarda olduğu gibi bu çalışmada da Herfindahl-Hirschman Endeksi (HHI)'nden faydalanılmıştır. HHI ile ekonomik büyüme göstergesi GSYİH arasındaki ilişkiyi iki farklı ülke grubu için analiz edildiği panel veri analiz yöntemi sonuçlarında, OGT ülkelerinin belirli bir gelir seviyesine ulaşıncaya kadar ihracatta ürün çeşitliliğine, KOGT ülkeleri ise, ihracatta ürün çeşitliliğinden ziyade ihraç ürünlerinde uzmanlaşmaya yönelmeleri gerektiği sonucuna ulaşılmıştır.

Ancak bu aşamada, OGT ülkelerinin bazı ekonomilerin geleneksel ürünlerden geleneksel olmayan ürünlere doğru çeşitlendirme yapmasını kolaylaştıran veya engelleyen faktörlerin neler olduğunun araştırılması önem kazanmaktadır. Rodrik (2009)'a göre, az gelişmiş ülkelerin ürün çeşitlendirmek amacıyla geleneksel olmayan ürünler için yatırım yapılmasını engelleyen "enformasyon” ve "koordinasyon" dişsallıkları söz konusudur (Rodrik, 2009,s. 112).

Hausmann ve Rodrik (2003) tarafindan ortaya atılan "maliyet keşfi (cost discovery)" diğer bir ifadeyle "enformasyon dişsallığı (knowledge externalities)" kavramından yola çıkılarak, Hausmann vd. (2007) çalışmasında, bir girişimcinin 
herhangi bir yeniliği ortaya koyması için kayda değer bir maliyete katlanmak zorunda kalması gerektiğinden bahsedilmektedir. Bu süreçte gelişmekte olan bir ülkede yenilik gerçekleştirmek isteyen bir girişimci maliyet belirsizliğine maruz kalmaktadır. Maliyet keşfi sürecine katılan girişimcinin, toplumsal kazançlarını özel kazanımlardan daha büyük hale getiren bu enformasyon dişsallığı, serbest kullanım (bedavacılık) problemine yol açmaktadır. Mevcut ürünlerin ülke içerisinde taklit edilerek daha düşük maliyetle üretilmesini sağlayan bu süreç, yeni mal ve hizmetlerin üretimi için azda olsa gerekli olan keşif maliyeti, ihtiyaç duyulan teknoloji alımı ve girişimcinin keşif rantını düşüren enformasyon dışsallığı gibi durumlar dolayısıyla çeşitli piyasa aksaklıkları yaşanmaktadır. $\mathrm{Bu}$ durum, niteliksiz, yetersiz yatırımların yapılmasına ve gelişmekte olan ülkelerin aynı gelir düzeyinde uzun süre kalmasına, diğer bir ifadeyle orta gelir tuzağına yakalanmalarına sebep olmaktadır (Rodrik, 2009).

OGT grubunda ihracat çeşitlenmesini engelleyen bir diğer önemli faktör ise koordinasyon dışsallıklarıdır. Koordinasyon dışsallığı, yapılan projelerin kara geçmesini sağlayan eşzamanlı yatırımların gerçekleştirilmesinde oluşan belirsizliklerdir (Rodrik, 2009).

Her iki dışsallık türünün giderilmesi amacıyla özellikle OGÜ’nün mevcut ihracat yapısını değiştirip, yapısal dönüşümün sağlanması için inovatif faaliyetlere dayalı bir büyüme trendini yakalamaları gerektiği söylenebilir (Zeufack ve Lim (2013); Kanapathy vd. (2014); Kang vd. (2015)). Gelişmekte olan ülkede ihracat çeşitlendirmesini gerçekleştirmeyi amaçlayan firmalar, inovatif ve teknolojik gelişmeler ile maliyetlerini azaltarak, ihracattaki mevcut pazar paylarını arttırıp ürün farklılaştırmasını gerçekleştirmeyi hedeflerler. $\mathrm{Bu}$ doğrultuda, diğer bölümlerde mevcut ihracat çeşitliliği ile hedeflenen büyüme trendini yakalayamayacağı düşünülen orta gelir tuzağına takılmış olan ülkeler için inovasyona dayalı modelinin gerekliliği savunulmaktadır.

\section{Kaynakça}

Age'nor, PR, Canuto, O \& Jelenic, M. (2012). Avoiding middle-1ncome growth traps. economic premise, Poverty Reduction and Economic Management Network (PREM), The World Bank, 98.

Acemoglu, D., \& Zilibotti, F. (1997). Was prometheus unbound by chance? Risk, diversification, and growth. Journal of Political Economy, 105(4), 709751.

Agosin, M. R. (2007). Export diversification and growth in emerging economies. Santiago, University of Chile.

Agosin, M. R., Alvarez, R., \& Bravo- Ortega, C. (2012). Determinants of export diversification around the world: 1962-2000. The World Economy, 35(3), 295-315. 
Aiyar, M. S., Duval, M. R. A., Puy, M. D., Wu, M. Y., \& Zhang, M. L. (2013). Growth slowdowns and the middle-income trap. International Monetary Fund, (13/71).

Ali, R., Alwang, J. R., \& Siegel, P. B. (1991). Is export diversification the best way to achieve export growth and stability?: a look at three African countries (Vol. 729). World Bank Publications.

Al-Marhubi, F. (2000). Export diversification and growth: an empirical investigation. Applied Economics Letters, 7(9), 559-562.

Aoiki, M. (2011).The five-phases of economic development and institutional evolution in China and Japan. ADBI Working Paper Series, 340.

Arip, M.A., L.S. Yee \& B. Abdul Karim. (2010). Export diversification and economic growth in malaysia. Munich Personal Repec Archive (MPRA), 20588.

Ay, A., Akar, G., \& Akar, T. (2016). Middle income trap: a comparison between BRICS countries and Turkey. Economic and Environmental Studies, 16(2 (38)), 279-301.

Balaguer, J., \& Cantavella-Jorda, M. (2004). Structural change in exports and economic growth: cointegration and causality analysis for Spain (19612000). Applied Economics, 36(5), 473-477.

Baltagi, B. (2005). Econometric analysis of panel data. John Wiley \& Sons.

Bartz, C. (2010). Export diversification and growth in Sub-Saharan Africa (Doctoral dissertation, Master's thesis, Department of Economics, University of Amsterdam).

Bebczuk, R. N. \& Berrettoni, N. D. (2006) Explaining export diversification: an empirical analysis, CAF research program on development issues, Department of Economics, Universidad Nacional de La Plata.

Berthelemy, J. C., \& Chauvin, S. (2000). Structural changes in Asia and growth prospects after the Crisis. CEPII Working Papers, 00-09

Bonaglia, F., \& Fukasaku, K. (2003). Export diversification in low-income countries: an international challenge after DOHA. OECD Development Centre, 209. 
Bulman, D., Eden M. \& Nguyen, H. (2014) Transitioning from low-1ncome growth to high-income growth - Is there a middle income trap. Policy Research Working Paper No. 7104, World Bank.

Çeviker, A. ve Taş, İ. (2011), Türkiye'de ihracat çeşitlendirmesi ve büyüme ilişkisi, Ekonomi Bilimleri Dergisi, 3(2), 1-10.

Dennis, A., \& Shepherd, B. (2007). Barriers to entry, trade costs and export diversification in developing countries. The World Bank Policy Research Working Paper, 4(368), 1-40.

Dewitte, R. (2014). Middle income trap and export sophistication: assessment and economic policy implications. Unpublished Master Thesis, Ghent: Ghent University Faculty of Economic and Business Administration.

Doner, R. F. \& Schneider B. R. (2016). The middle-income trap: more politics than economics. World Politics, 68(4), 608-644.

Egawa, A. (2013). Will income inequality cause a middle-income trap in Asia? 797, Bruegel.

Eichengreen, B. \& Park, D. ve Shin, K. (2011). When fast growing economies slow down: international evidence and implications for China, NBER Working Paper Series, 16919, National Bureau of Economic Reseaarch, March.

Eichengreen, B. \& Park, D. ve Shin, K. (2013). Growth slowdowns redux: new evidence on the middle-income trap, NBER Working Paper Series, 18673, National Bureau of Economic Reseaarch.

Fonchamnyo, D. C., \& Akame, A. R. (2017). Determinants of export diversification in Sub-Sahara African region: a fractionalized logit estimation model. Journal of Economics and Finance, 41(2), 330-342.

Felipe, J., Abdon, A., \& Kumar, U. (2012). Tracking the middle-income trap: What is it, who is in it, and why?. Levy Economics Institute, Working Paper, 715.January.

Ferdous, F. B. (2011, February). Pattern and determinants of export diversification in East Asian economies. In Proceedings of the International Conference on Social Science and Humanity, Singapore, 2628. 
Fotros, M. H., Nemati, M., \& Darabi, H. (2013). Relationship between export diversification and economic growth. International Journal of Basic Sciences \& Applied Research. 2 (12), 991-999.

Foxley, A. \& Sossdorf, F. (2011). Making the transition from middle-income to advanced economies. Carnegie Endowment, The Carnegie Papers.

Gill, I. \& Kharas, H. (2007). An East Asian renaissance - Ideas for economic growth. Washington, DC: World Bank.

Glawe, L., \& Wagner, H. (2016). The Middle-Income Trap: Definitions, Theories and Countries Concerned-A Literature Survey. Comparative Economic Studies, 58(4), 507-538.

Gutiérrez de Pineres, A. S. \& Ferrantino, M.J. (2000) Export dynamics and economic growth in latin america, Ashgate, Aldershot, England.

Hartwell, C. (2013). The growth elixir: Escaping the middle 1ncome trap in emerging market. Institute for Emerging Market Studies, Brief 13

Hausmann, R., \& Rodrik, D. (2003). Economic development as self-discovery. Journal of development Economics, 72(2), 603-633.

Hausmann, R., F. Rodriguez, \& R. Wagner (2008). Growth collapses. C. Reinhart, C. Vegh, \& A. Velasco, eds., Money, Crises and transition. Cambridge: OGT Press.

Hausmann, R., Hwang, J., \& Rodrik, D. (2007). What you export matters., Journal of economic growth, 12(1), 1-25.

Hausmann, R., \& Hidalgo, C. (2010). Country diversification, product ubiquity, and economic divergence. HKS Working Paper No. RWP10-045

Herzer, D., \& Nowak-Lehnmann D, F. (2006). What does export diversification do for growth? An econometric analysis. Applied economics, 38(15), $1825-1838$.

Hesse, H. (2008). Export diversification and economic growth. Working Paper No.21. Commission on Growth and Development. World Bank, Washington, DC

Hirsch, S., \& Lev, B. (1971). Sales stabilization through export diversification. The Review of Economics and Statistics, 270-277. 
Islam, N. (2013). Beyond the middle income trap: what kind of high income country can china become?. The International Centre for the Study of East Asian Development, 20, 1-26

Islam, S. N. (2015). Will Inequality Lead China to the Middle Income Trap?. DESA Working Paper N. 142.

Kanchoochat, V. \& Intarakumnerd, P. (2014). Tigers Trapped: Tracing the Middle-income Trap through the East and Southeast Asian Experience. Berlin Working Papers on Money, Finance, Trade and Development, Working Paper No. 04/2014.

Kanapathy, V., Hazri, H., Phongpaichit, P., \& Benyaapikul, P. (2014). Middle income trap: Economic myth, political reality. The Asia Foundation, Internet Address: http://asiafoundation. org/publications/pdf/1277, (Erişim tarihi, 25,01. 2014).

Kang, H. (2015). Agricultural exports and economic growth: Empirical evidence from the major rice exporting countries. Agricultural Economics - Czech, 61(2): 81-87.

Kao, C. (1999). Spurious regression and residual-based tests for cointegration in panel data. Journal of econometrics, 90(1), 1-44.

Kharas, H., \& Kohli, H. (2011). What is the middle income trap, why do countries fall into it, and how can it be avoided?. Global Journal of Emerging Market Economies, 3(3), 281-289.

Levin, A., Lin, C. F., \& Chu, C. S. J. (2002). Unit root tests in panel data: asymptotic and finite-sample properties. Journal of econometrics, 108(1), $1-24$.

Lin, J.Y. (2012). Demystifying the Chinese economy, Cambridge. Cambridge University Press

Love, J. (1986). Commodity concentration and export earnings instability: A Shift from Cross-Section to time series analysis. Journal of Development Economics, 24, 239-248.

Lugeiyamu, E. (2016). Is export diversification a key force to africa's economic growth?:cross-country evidence. Jönköping University 
Luiz, J. M. (2016). The political of economy middle income traps: Is South Africa in a long-run growth trap? the path to bounded populism. South African Journal of Economics, 86 (1),3-19

Markowitz, H. (1952). Portfolio selection. The journal of finance, 7(1), 77-91.

Matthee, M., \& Naudé, W. (2007). Export diversity and regional growth: empirical evidence from South Africa (No. 2007/11). Research Paper, UNU-WIDER, United Nations University (UNU).

Mau, K. (2014).Margins, gravity and causality: export diversification and income levels reconsidered. GIGA Working Papers no. 249. GIGA German Institute of Global and Area Studies Hamburg, Germany

Mudenda, C., Choga, I., \& Chigamba, C. (2014). The role of export diversification on economic growth in South Africa. Mediterranean Journal of Social Sciences, 5(9), 705.

Naudé, W., \& Rossouw, R. (2008). Export diversification and specialization in South Africa: Extent and impact (No. 2008.93). Research paper/UNUWIDER.

Nicet-Chenaf, D., \& Rougier, E. (2008). FDI, diversification and growth: An empirical assessment for mena countries. IMF Staff Papers, 40, 151-172.

Ohno, K. (2009). Avoiding the middle-income trap: renovating industrial policy formulation in Vietnam. ASEAN Economic Bulletin, 26(1), 25-43.

Olaleye, S. O., Edun, F., \& Taiwo, S. B. (2014). Export diversification and economic growth in Nigeria: An empirical test of relationship using a granger casualty test. Journal of Emerging Trends in Economics and Management Sciences, 5(1), 70.

Öztürk, S., \& Altınöz, B. (2018), İmalat Sektörü Firma Karlılığının Ekonomik Büyüme Üzerindeki Etkisi: Türkiye İçin Bir Uygulama. Ömer Halisdemir Üniversitesi İktisadi ve İdari Bilimler Fakültesi Dergisi, 11(3), 18-25.

Parteka, A. \& M. Tamberi (2008). Determinants of export diversification: An empirical investigation. Working Paper 327

Pedroni, P., (2000). Fully modified OLS for heterogeneous cointegrated panels. Advanced in Econometrics, 15, 93-130 
Pedroni, P. (2004). Panel cointegration: asymptotic and finite sample properties of pooled time series tests with an application to the PPP hypothesis. Econometric Theory, 20(3), 597-625.

Petersson, L. (2005). Export diversification and intra- industry trade in South Africa. South African journal of economics, 73(4), 785-802.

Pesaran, M.H., Shin, Y. \& Smith, R.J. (1999). "Pooled Mean Group Estim8ation of Dynamic Heterogeneous Panels". Journal of the American Statistical Association, 94(446).

Pesaran, M. H. (2004). General diagnostic tests for cross section dependence in panels. CESifo Working Paper Series No. 1229; IZA Discussion Paper No. 1240

Pesaran, M. H. (2007). A simple panel unit root test in the presence of crosssection dependence. Journal of applied econometrics, 22(2), 265-312.

Pirasteh, H., Sayadi, M., \& Saghafi, M. (2009). Economic growth and stability in the Euro-Med Region: Concentration or diversification?. Iranian Economic Review, 14(23), 105-130.

Pritchett, L. (2000). Understanding patterns of economic growth: searching for hills among plateaus, mountains, and plains. The World Bank Economic Review, 14(2), 221-250.

Reddy, S., \& Miniou C. (2006). Real income stagnation of countries, 19602001.Columbia University, New York. Unpublished

Robertson, P. E. \& Ye, L. (2013). On the existence of a middle income trap, University of Western Australia Economics Discussion Paper 13.12.

Rodrik, D. (1999). Where did all the growth go? Wxternal shocks, social conflict and growth collapses. Journal of Economic Growth 4, 385-412.

Rodrik, D. (2009). Tek ekonomi çok reçete küreselleşme, kurumlar ve ekonomik büyüme, N. Domaniç (Çev.), Ankara: Eflatun Yayınevi.

Ros, J. (2005).Divergence and growth collapses: Theory and empirical evidence. In J. A. Ocampo, ed., Beyond Reforms: Structural dynamics and macroeconomic vulnerability. Stanford: Stanford University Press.

Samen, S. (2010). Export development, diversification and competitiveness: how some developing countries got it right. World Bank Institute. 
Tatoğlu, F. (2017). Panel Zaman Serileri Analizi, Beta Yayınevi, 1

Tho, T. V. (2013). The middle-income trap: Issues for members of the Association of Southeast Asian nations. Asian Development Bank Institute Working Paper, 421.

UnctadStat, 2018, (United Nations Conference On Trade and Development) http://unctadstat.unctad.org/EN/ (Erişim tarihi: 25.02.2018)

Woo, W.T. (2012). China meets the middle-income trap: the large potholes in the road to catching-up. Journal of Chinese Economic and Business Studies, 10(4), 313-336.

Zeufack, A., \& Lim, K. Y. (2013). Can malaysia achieve innovation-led growth?. Khazanah Nasional (Kuala Lumpur: 2013). 


\section{An Investigation of the Relationship between Export Product Diversification and Economic Growth in the context of Middle Income Trap}

\section{Extended Abstract}

\section{Introduction}

The concept of middle income trap (MIT) defined as countries remain within the same income group for a certain period of time. The countries in MIT deal with many macroeconomic problems at the international competitiveness level. The concept of MIT was firstly mentioned in the report of an East Asian Renaissance-Ideas for Economic Growth. In this report, the countries in MIT were mentioned as countries that entered into a period of serious growth and integration after the 19th century, which increased to the middle income level but could not catch up the international competitiveness level in the later periods and became trapped in the middle income. In general, there are two main approaches to the concept of middle income trap. These are the approaches proposed by Kharas and Kohli (2011) examining the concept of middle income trap in terms of supply and Lin (2012). While Kharas and Kohli (2011) states that the development strategy of countries should change from low income to middle-income country status, Lin (2012) argues that there is no need for any strategy change. Lin (2012)'s approach is divided into two approaches: CAD- Comparative Advantage-Defying and CAF-Comparative Advantage Following (Islam, 2013, pp. 1-6). There are many studies investigating the risk of entry of countries into MIT on which thresholds. These are Eichengreen et al. (2011, 2013), Felipe et al. (2012), Aiyar et al. (2013), Woo et al. (2012), Robertson and Ye (2013) and Bulman et al. (2014). However, it can be stated that the theoretical basis of MIT is constructed by Maltusian Trap, Lewis's Dual Structure Model and Solow's growth theory. Kanchoochat and Intarakumnerd (2014) argue that countries should follow the strategies, called "Changing and Diversification of Export Composition" defined as a change in the export composition and structure of the country in order to be able to avoid or escape from MIT.

In the light of the above mentioned, this study aims to investigate the impact of export diversification on economic growth following Kanchoochat and Intarakumnerd (2014) for countries in the middle-income trap, and countries escaped from the middle income trap.

\section{Method}

This study aims to establish a link between the middle income trap and the diversification of export products utilizing Robertson and Ye (2013) approach for selected countries. In this context, selected countries identified as countries in the middle-income trap (MIT), including Brazil, Mexico, Malaysia and Turkey, and countries escaped from the middle income trap (NMIT), namely, South Korea, Portugal, Singapore, and Greece.

The Herfindahl-Hirschman Index (HHI) extracted from UNCTADSTAT database was used as a product diversity (intensity) in exports. The data set of per capita income growth in 2010 with fixed \$ prices was obtained from World Bank data. In order to determine the relationship between export diversity and economic growth, firstly Pesaran (2004) test utilized to examine whether there is a cross-sectional dependence between variables.

CD test for balanced panel is shown below (Tatoglu, 2017, p. 105).:

$C D=\sqrt{\left(\frac{2 T}{N(N-1)}\right)} \sum_{i=1}^{N-1} \sum_{j=i+1}^{N}\left(\hat{\rho}_{i j}-1\right) \square N(0,1)$ 
After confirmation of cross-sectional dependence between variables for the panel group, CADF (Cross-Sectional Augmented Dickey-Fuller) unit root test used developed by Pesaran (2007). CIPS is the average of CADF statistics is shown below (Pesaran, 2007, p. 276):

$C I P S=\frac{1}{N} \sum_{i=1}^{N} t_{i}(N, T)$

In this context, the long and short-term relationship between variables analyzed utilizing ARDL methodology proposed by Pesaran et al. (1999). In the study, the relevant panel ARDL long-run equations can be expressed as;

$G S Y H_{i t}=\sum_{k=1}^{p} G S Y H_{i, t-k} \emptyset_{i k}+\sum_{k=0}^{q} H H I_{i, t-k} \partial_{i k}+\mu_{i}+\varepsilon_{i t}$

Also, the error correction model for the Panel ARDL methodology below were estimated;

$$
\Delta G S Y H_{i t}=\partial_{i}\left(G S Y H_{i, t-1}-Q_{t} H H I_{i t}\right)+\sum_{k=1}^{p-1} \vartheta_{i k} \Delta G S Y H_{i, t-1}+\sum_{k=0}^{q-1} \alpha_{i k} \Delta H H I_{i, t-k}+\mu_{i}+\varepsilon_{i t}
$$

\section{Results and Discussion}

In the first stage of the analysis, according to Pesaran (2004) test results, it is concluded that there is a dependency between the cross sections for both groups. For this reason, CIPS unit root test, which is the average of CADF statistics performed in case of cross-sectional dependency. As a result of the unit root test, it is seen that the GDP and HHI variables have a unit root at level. On the other hand, unit root test reveals that the first differences of all the variables are stationary for both groups. In order to determine the long-term relationship between the variables after the unit root test applied to the variables, it was concluded that the results of the Panel ARDL/PMG estimator should be used for both countries. According to the panel ARDL / PMG results, MIT countries are negatively affected by the export diversity in the long term and the NMIT countries are positively affected.

\section{Conclusion}

According to the results, while MIT countries should focus on product diversification in exports, NMIT countries should focus on specialization. Put in differently, unlike MIT countries, NMIT countries' economic growth is positively affected by export intensity and specialization in the export of certain product and product groups rather than diversifying their exports. According to the findings, it can be clearly stated that the MIT group should focus on diversification in their exports to a certain level of income.

However, it is important to investigate the factors lying behind MIT countries to diversify their products from traditional products to non-traditional products.

Rodrik (2009) indicates that there are some "information" and "coordination" externalities preventing the investment of non-traditional products in order to diversify the products of underdeveloped countries (Rodrik, 2009, p. 112). Hausmann and Rodrik (2003) use the concept of knowledge externalities to explain the cost of discovery. Hausmann et al. (2007) indicate that an entrepreneur must have to undertake a significant cost to invest any innovation. In this process, an entrepreneur who wants to invest in a developing country is exposed to uncertainty in cost estimates. This information externality makes the entrepreneur's the cost of discovery bigger than the private gains leading to the free rider problem. This process enabling the existing products to manufacture in a country with a lower cost experiences a variety of market failures due to the cost of the exploration, the technology needed for the production of new goods and services, and the externalities of the information that reduce the explorer's profit. This situation leads to inadequate, insufficient investments making developing countries stay at the same income level for a long time, in other words, it causes them to enter into the middle income trap (Rodrik, 2009). 
Another important factor that prevents export diversification in the MIT countries is the coordination of externalities. Coordination externality defined as an uncertainty in the realization of simultaneous investments allowing the projects to make profit (Rodrik, 2009). In order to eliminate both types of externality, it can be said that MIT countries should change its current export structure and achieve a growth trend based on innovative activities for achieving structural transformation (Zeufack and Lim (2013); Kanapathy et al. (2014); Kang et al. (2015)). 